PAPER • OPEN ACCESS

\title{
Maintenance Management Model under the TPM approach to Reduce Machine Breakdowns in Peruvian Giant Squid Processing SMEs
}

To cite this article: A Gallesi-Torres et al 2020 IOP Conf. Ser.: Mater. Sci. Eng. 796012006

View the article online for updates and enhancements.

The goal of ECS Sensors Plus, as a one-stop shop journal for sensors, is to advance the fundamental science and understanding of sensors and detection technologies for efficient monitoring and control of industrial processes and the environment, and improving quality of life and human health.

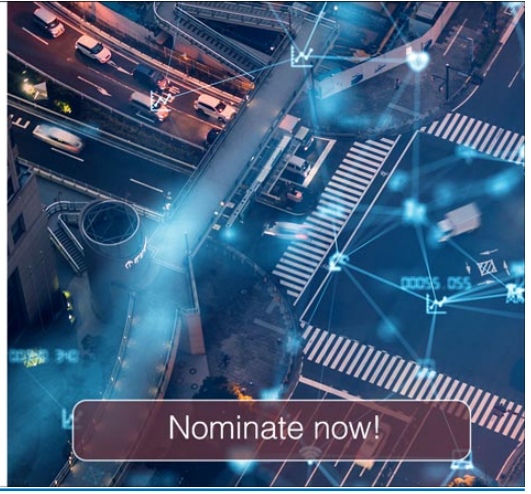




\title{
Maintenance Management Model under the TPM approach to Reduce Machine Breakdowns in Peruvian Giant Squid Processing SMEs
}

\author{
A Gallesi-Torres ${ }^{1}$, A Velarde-Cabrera ${ }^{1}$, C León-Chavarri ${ }^{1}$, \\ C Raymundo-Ibañez ${ }^{2,4}$ and F Dominguez ${ }^{3}$ \\ ${ }^{1}$ Ingeniería Industrial, Universidad Peruana de Ciencias Aplicadas (UPC), Lima \\ 15023, Perú. \\ ${ }^{2}$ Dirección de Investigación, Universidad Peruana de Ciencias Aplicadas (UPC), Lima \\ 15023, Perú. \\ ${ }^{3}$ Escuela Superior de Ingeniería Informática, Universidad Rey Juan Carlos, Mostoles, \\ 28933, España. \\ E-mail: carlos.raymundo@upc.edu.pe
}

\begin{abstract}
In recent years, the giant squid processing industry in Peru exhibited a 59\% increase in exports with respect to 2018 . According to estimates, this industry generates approximately 30,900 jobs per year. However, some SMEs experience low productivity, such as the PECEPE company, due to plant downtime. This represents $26 \%$ of the available time, which translates into the loss of 1760 tons every year. The most constraining external factor the sector faces is uncertainty in resource availability caused by changing weather conditions and informal fishing activities. Although there is a large number of research studies on the fishing industry and resource extraction, literature on processing plant operations is scarce. Within this context, this study seeks to promote a high impact sector in Peru, as well as fostering processing plant competitiveness and productivity. Hence, to address these issues, the authors propose a maintenance management model under the TPM approach. As part of the results from model implementation, a 39\% decrease was reported in plant downtime, while maintenance costs also decreased by $16 \%$, which, in turn, increased machine availability and production by 784 tons per year.
\end{abstract}

\section{Introduction}

Between 2008 and 2016, small-scale giant squid landings in Peru represented approximately 53\% of the world's total, with an average catch of 556,000 MT, thus turning Peru into the country with the highest historical resource capture record in the world. However, even though Peru ranks first in resource extraction, it ranks fourth in exports, with just a 7\% market share, which is due to the low levels of competitiveness exhibited by Peruvian hydrobiological resource processing plants [1]. According to the Peruvian Industry Chamber (SNI, for its Spanish acronym), the 127 companies currently operating in this sector reported daily production averages at 48 MT in 2016 [2]. However, the "Fish and Cephalopods of Peru" company, PECEPE, reports an average production of $30 \mathrm{MT} /$ day,

4 To whom any correspondence should be addressed. 
which denotes a gap in comparison to the sector due to low productivity. In 2018, the company reported its overall equipment effectiveness (OEE) rate at $52.15 \%$, which is below the $85 \%$ benchmark established for the manufacturing sector at the international level [3].

According to estimates, this industry generates approximately 30,900 jobs per year. The main external factors that affect this industry is uncertainty in resource availability as giant squids migrate depending on the weather conditions. The above, in addition to port infrastructure, acts of nature and the informality of fishing [4].

In this context, this research study seeks to promote a high impact sector in Peru, wherein most fishing companies are still under development. This is evidenced by the existing gap between the number of landings and the position currently held by the country in terms of resource exports at the global level. Another critical item is the lack of literature on improving operations and asset maintenance management in hydrobiological product processing plants as most of the sector plants are semi-automated and use processing lines [5]. However, there are vast opportunities for the development of value-added products. For example, countries such as China and India, which capture and land 50\% less resources than Peru, successfully triple Peruvian exports due to the greater added value offered by their products and the greater levels of competitiveness exhibited by their plants [6]. Therefore, this study seeks to contribute research to the sector which may contribute to improving productivity at the PECEPE giant squid processing plant by reducing machine breakdowns and their impact on increasing company profitability.

The proposal comprises a maintenance management model reinforced with lean manufacturing tools such as TPM, 6S, and continuous improvement. The pilot plan was implemented for 6 months in the giant squid ring production line - the company's flagship product.

The next section describes a literary review on the techniques used.

\section{Literary review}

\subsection{TPM}

Most TPM implementation case studies come from the manufacturing sector [7]. For instance, Gupta and Vardhan applied TPM to a renowned tractor manufacturing industry in India. Their study showed that, through TPM implementation, production costs were reduced, while OEE rates improved, which doubled revenue from sales and tripled profits over a three-year period [8] [9].

Different authors who applied TPM to manufacturing organizations identified several pre-TPM implementation issues, such as extremely high maintenance costs; emergency repairs being thrice as expensive as the actual cost; and extremely high equipment downtime numbers. Moreover, pre- and post-implementation OEE rate were calculated for each machine, determining a $15 \%-30 \%$ increase in OEE rates for the different machines [8] [9] [10] [11].

\section{2. $6 \mathrm{~S}$}

The integration of $5 \mathrm{~S}$ and security $(6 \mathrm{~S})$ is unique in the scheme proposed by Rodrigues. As opposed to previous studies that treat these elements independently, $6 \mathrm{~S}$ focuses on work safety by guaranteeing a clean, organized environment without unnecessary items on the way [12].

One of the successful cases found in the literature was in an ink manufacturing company, which used $6 \mathrm{~S}$ to improve overall productivity and efficiency rates at a corporate level. Here before and after organizational photography was used to evidence the benefits from $6 \mathrm{~S}$ implementation. Then, a $6 \mathrm{~S}$ Checklist audit validated that throughout the 8-week period in which it was deployed, the level of technique maturation was deemed as sustainable, thus ratifying the objective of the study. The benefits from implementing 6S in this company were an optimized use of workspace, less time spent in searching for materials and supplies, improvements in occupational safety and health, and complete elimination of accidents, hazards, and risks [13] [14]. 


\section{Contribution}

\subsection{Proposed Model}

Based on the articles selected from each typology, the proposed maintenance management model was developed using a TPM approach supported by $6 \mathrm{~S}$ implementation, as depicted in Figure 1. As a pilot plan, this model is deployed in the giant squid ring production line at the PECEPE plant.

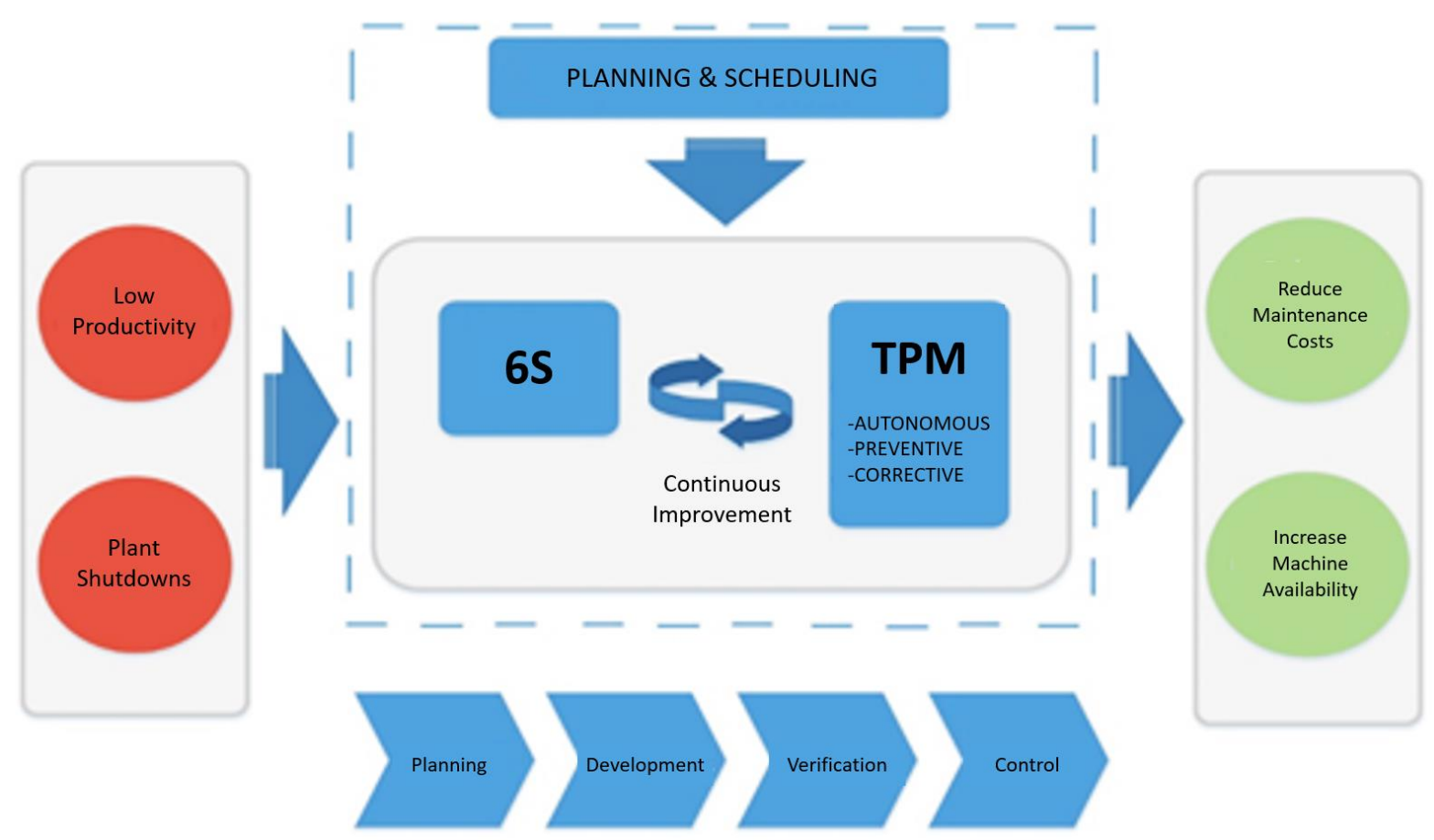

Figure 1. Maintenance management model with a TPM \& 6S approach

The model comprises the following main phases: planning, development, verification, and control.

1. Planning: in this phase, the main components that will serve as the foundation for the proposed model are defined and prepared.

2. Development: the 6S, autonomous maintenance, and planned maintenance tools are implemented.

3. Verification: the techniques applied are assessed and measured through indicators that verify compliance with the objectives proposed.

4. Control: the sustainability of model techniques within the maintenance process is monitored through documentation. Opportunities for improvement are reviewed through feedback and new techniques are proposed.

\subsection{Proposed Process}

The improvement proposal deployed in the giant squid ring production line at PECEPE focuses on the PDCA cycle and on TPM and 6S implementation. This way, the model seeks to reduce plant downtime due to machine breakdowns, thus increasing productivity in giant squid processing.

Figure 2 denotes the model development stages. 


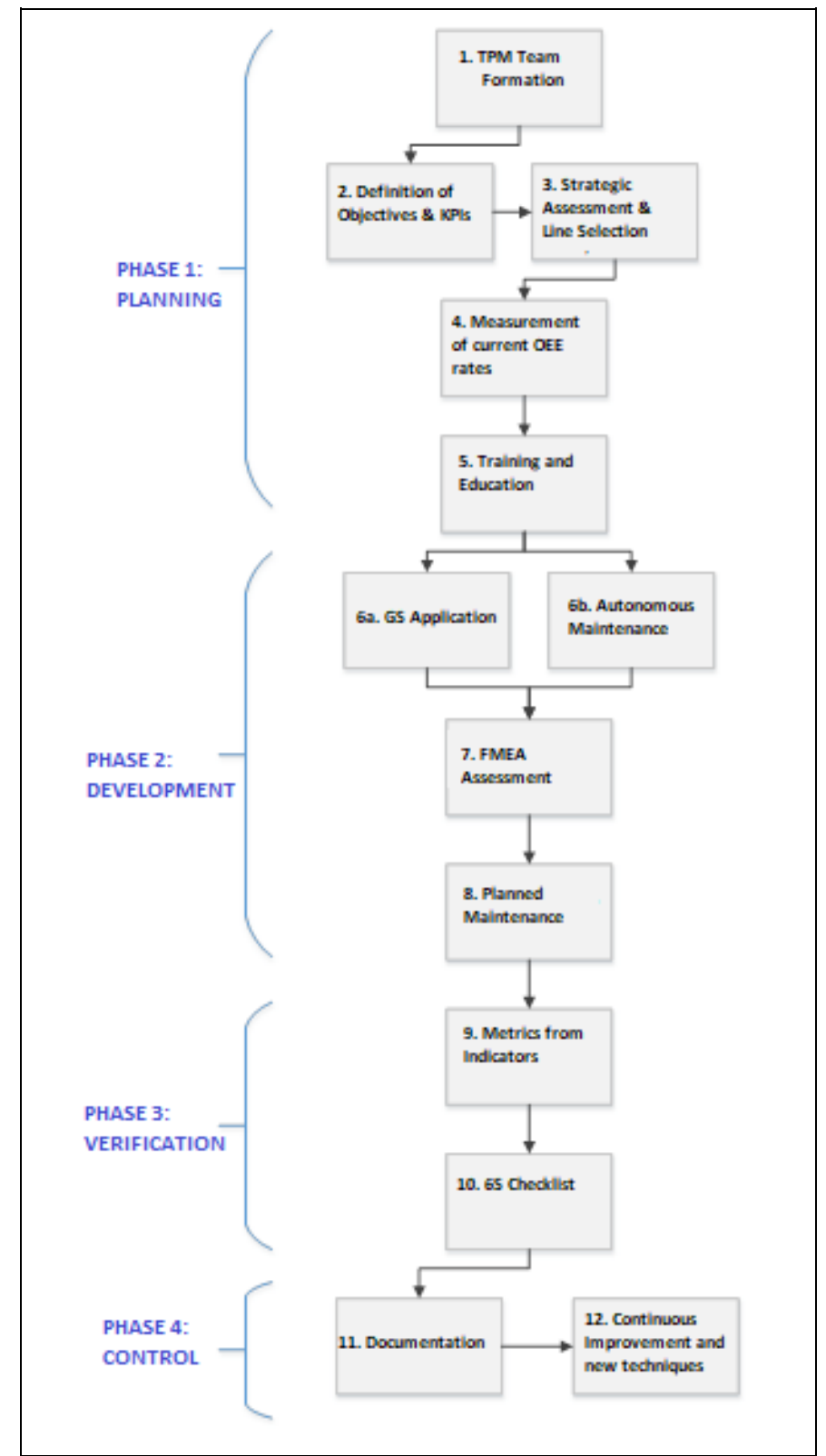

Figure 2. TPM application diagram

\subsection{Indicators}

Based on the proposed objectives, the following indicators were set forth to measure and control the parameters required by the company.

3.3.1. Equation 1: Overall Equipment Efficiency. This metric denotes the percentage of planned production time that is truly productive. It measures increases in availability, performance, and quality for the selected production line and is used to determine the success rate of TPM application.

$$
\text { OEE }=\text { Availability } \times \text { Performance } \times \text { Quality }
$$




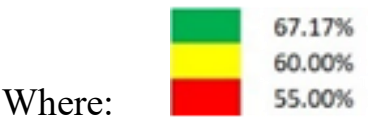

3.3.2. Equation 2: Maintenance Compliance (CM). This metric measures the percentage of compliance with preventive maintenance plans.

$$
\begin{aligned}
& C M=\left(\frac{M R}{P M}\right) \times 100 \\
& \\
& \\
& \text { Where: } \quad \begin{array}{r}
80 \% \\
80 \%
\end{array}
\end{aligned}
$$

3.3.3. Equation 3: Unscheduled Plant Downtime. Quantifies unscheduled plant downtime at the giant squid ring production line level.

$$
\begin{gathered}
\text { Unscheduled Downtime }=\frac{\text { Downtime }}{\text { Available Time }} \\
\text { Where: } \\
50 \% \\
40 \% \\
30 \%
\end{gathered}
$$

\section{Validation}

\subsection{Successful Case}

The company under study, "Fish and Cephalopods of Peru," PECEPE, has been in operation for five years in the market. It is located at 18th Km, South Pan-American Highway, within the Esmeralda Corp facilities. The pilot plan was developed in the production area, which comprises four semiautomated lines: giant squid rings, tentacles, neck, and paste. The company employs seven workers in the production area, while the rest of the plant operators are outsourced at hourly rates. An ABC analysis deemed giant squid rings as the company's flagship product as it represents more than $25 \%$ of the total sales from previous years.

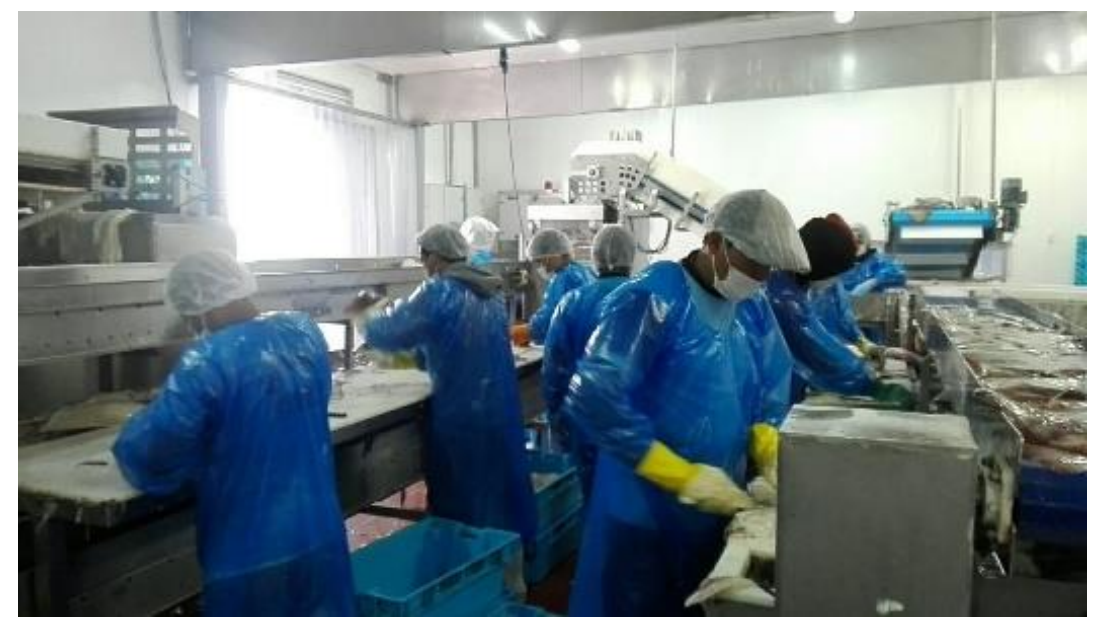

Figure 3. Inside the PECEPE plant 


\subsection{Diagnosis}

The company faces low productivity issues caused by downtimes of approximately 15.8 hours per week, which is equivalent to $26.4 \%$ of the entire production time. This generates an annual economic impact of $\$ 893,693.00$ as its average daily production capacity (30 MT/day) is below the average production rates reported for the sector (48 MT/day). Similarly, current OEE rates for the giant squid production line are at $52.15 \%$ in contrast to the world-class OEE standard rates at $85 \%$.

Table 1. World-Class OEE standard rates

\begin{tabular}{ccc}
\hline OEE Factors & $\begin{array}{c}\text { World Class } \\
\text { Standard }\end{array}$ & OEE PECEPE \\
\hline Availability & $90.00 \%$ & $73.61 \%$ \\
Efficiency & $95.00 \%$ & $71.98 \%$ \\
Quality & $99.90 \%$ & $98.43 \%$ \\
General OEE & $85.00 \%$ & $52.15 \%$ \\
\hline
\end{tabular}

As determined, this low productivity was mainly caused by machine breakdowns and delays in repairs $(64 \%)$, the plant disorganization $(12 \%)$, and reprocessing $(7 \%)$.

\subsection{Model Application}

4.3.1. Planning. Within the first phase, the following actions are performed:

- Establishment of a Maintenance Team

- Strategic Assessment and Production Line Selection

- Measuring of Current OEE Rates

- Training and Education

\subsubsection{S Implementation}

Applying the checklist $6 \mathrm{~S}$ helps to clean and organize the workplace in order to facilitate the solution of the problem and as a basis for the implementation of the TPM. The checklist shows a score based on infractions for each item. If the score is greater than 75 then it is satisfactory.

After deploying $6 \mathrm{~S}$ in the plant for two months, the $6 \mathrm{~S}$ Checklist was applied for auditing purposes. In this case the score was 90, rated as optimal (the list was complete at 90\%). 
The 9th AIC 2019 on Sciences \& Engineering (9thAIC-SE)

IOP Publishing

IOP Conf. Series: Materials Science and Engineering 796 (2020) 012006 doi:10.1088/1757-899X/796/1/012006

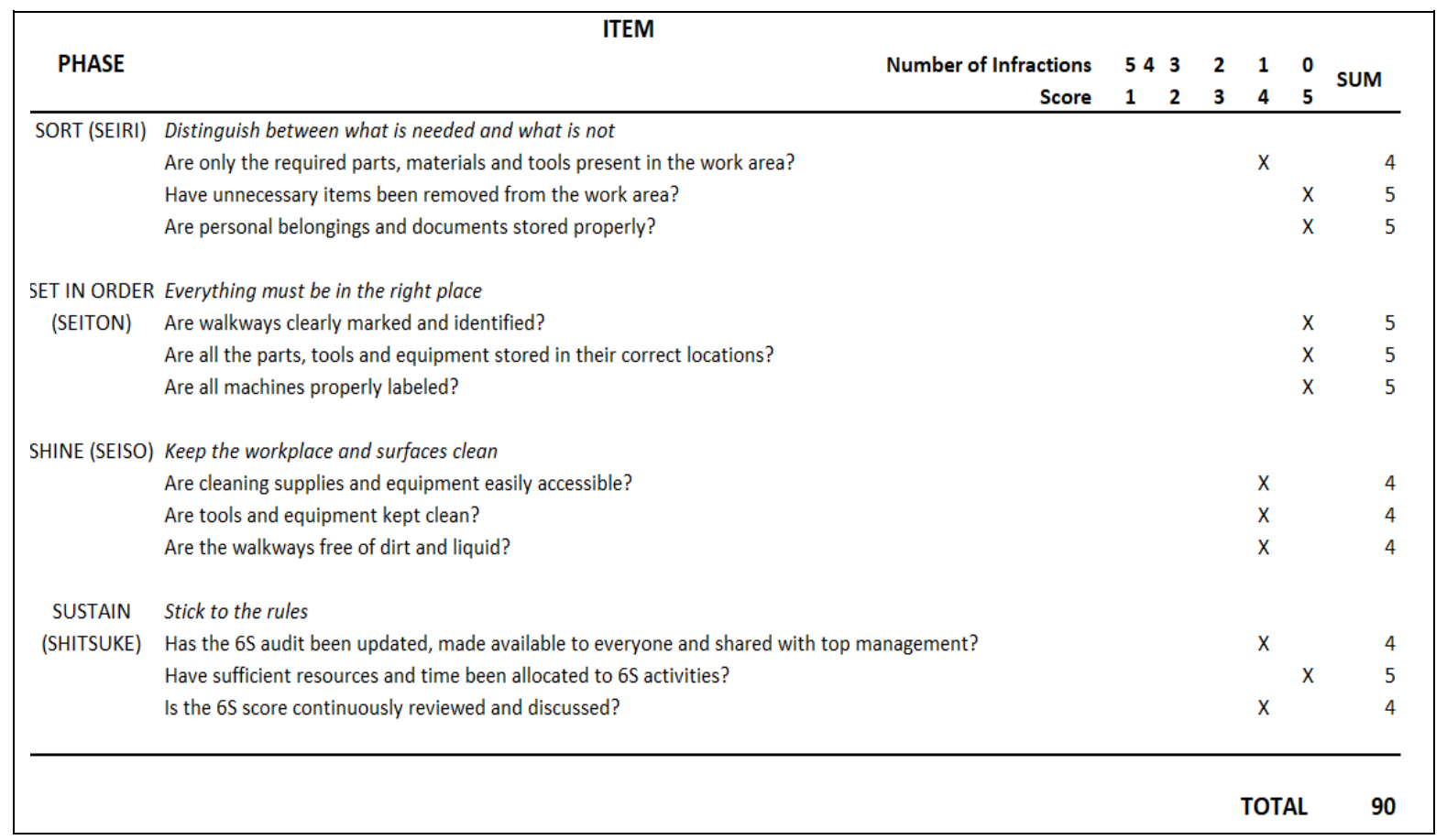

Figure 4. 6S Checklist. Note: Obtained from PECEPE.

As per the authors, any score above 75 is considered excellent. In this case, the final score of 90 renders the $6 \mathrm{~S}$ implementation at the PECEPE plant as successful.

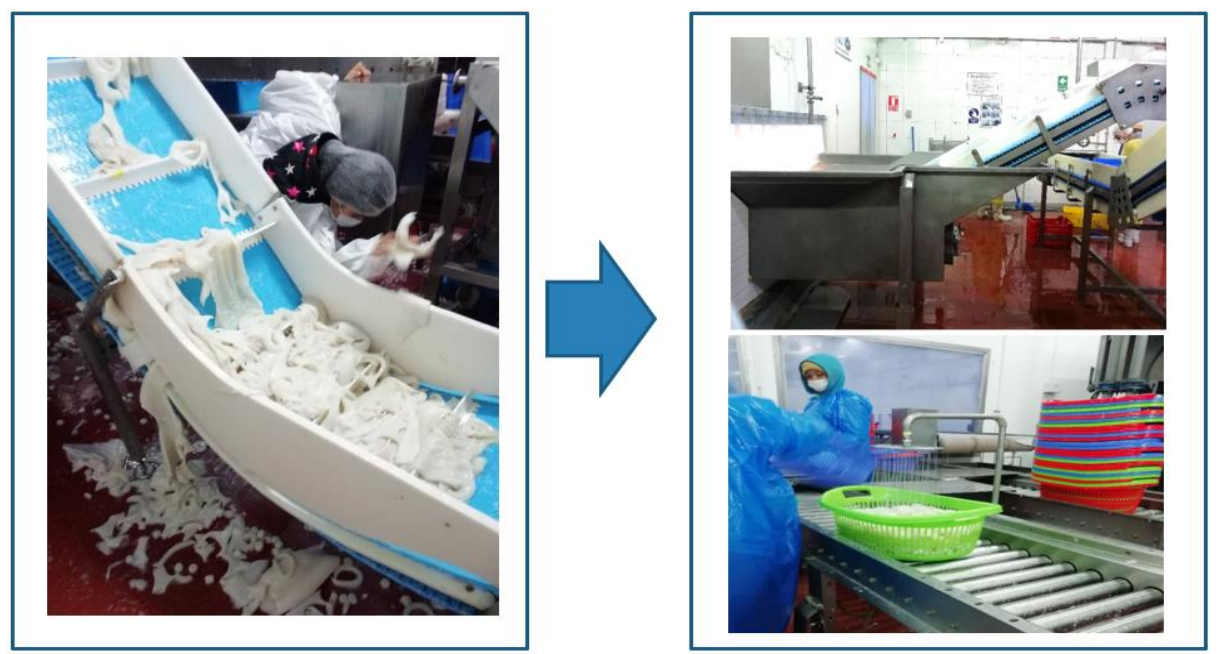

Figure 5. The Giant Squid ring production line before and after $6 \mathrm{~S}$ application.

\subsubsection{Autonomous Maintenance Application}

The flowchart depicting the autonomous maintenance procedure was developed. Pre- and postapplication results are presented below: 
The 9th AIC 2019 on Sciences \& Engineering (9thAIC-SE)

IOP Publishing IOP Conf. Series: Materials Science and Engineering 796 (2020) 012006 doi:10.1088/1757-899X/796/1/012006

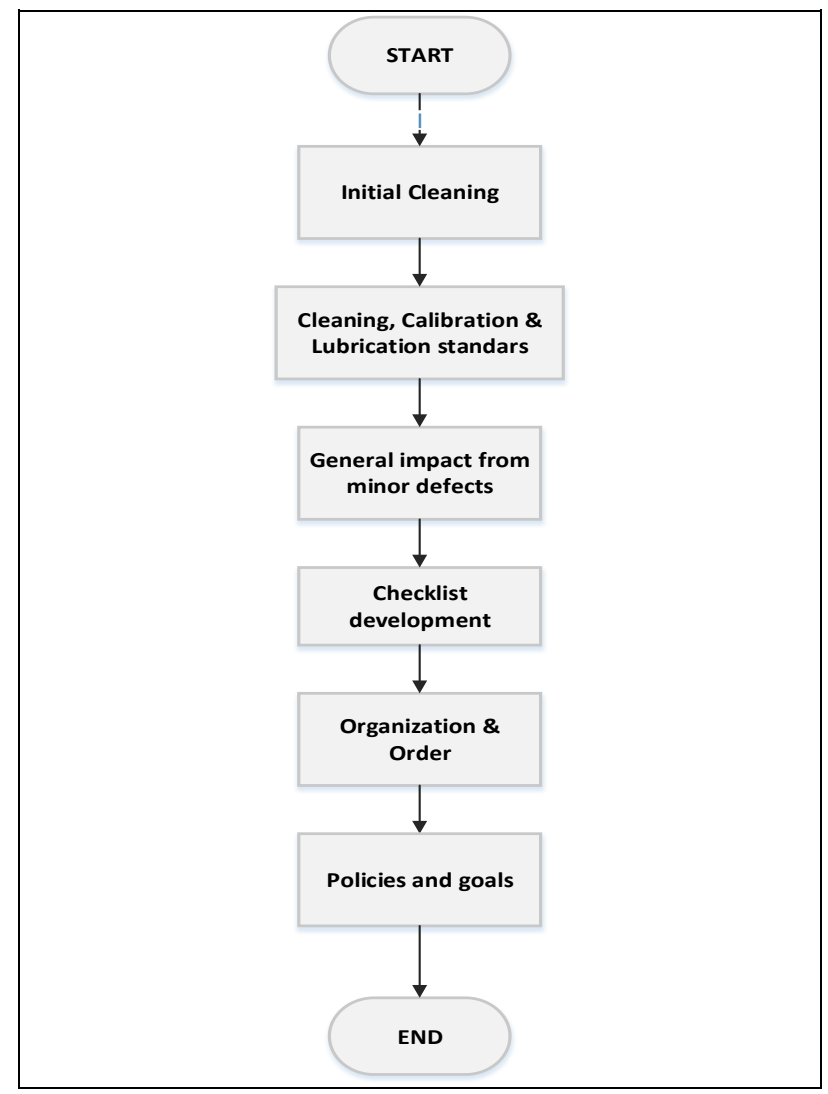

Figure 6. Autonomous maintenance flowchart

\begin{tabular}{|c|c|c|c|c|c|c|c|}
\hline \multicolumn{8}{|c|}{ GIANT SQUID RINGS PRODUCTION LINE } \\
\hline \multirow[b]{2}{*}{ Activity } & BEFORE & & \multirow[b]{2}{*}{$\begin{array}{r}\text { Initial Time per } \\
\text { Month (Min) } \\
\end{array}$} & \multicolumn{4}{|c|}{ AFTER } \\
\hline & $\begin{array}{c}\text { Maintenance } \\
\text { Type } \\
\end{array}$ & Frequency & & Activity & Maintenance Type & Frequency & $\begin{array}{l}\text { Final Time per } \\
\text { Month (Min) }\end{array}$ \\
\hline Bearings Greasing & Preventive & Weekly & 220 & Clean Work Area & Autonomous & Daily & 200 \\
\hline Megging of Electric Engine & Preventive & Weekly & 360 & Clean Conveyor Belt & Autonomous & Daily & 360 \\
\hline Check Electrical System & Preventive & Weekly & 720 & Filter Cleaning & Autonomous & Daily & 200 \\
\hline Change Weighing Card & Preventive & Weekly & 400 & Bearings Lubrication & Autonomous & Daily & 300 \\
\hline Band Tape Check & Preventive & Weekly & 320 & Band Check & Autonomous & Daily & 200 \\
\hline Blade Changes & Corrective & Weekly & 260 & Chain Adjustments & Autonomous & Daily & 200 \\
\hline Gear Change & Corrective & Weekly & 800 & Blade Changes & Preventive & Monthly & 20 \\
\hline Blade Sharpening & Corrective & Weekly & 120 & Gear Change & Preventive & Monthly & 20 \\
\hline Suction Joint Adjustment & Corrective & Weekly & 140 & Check Electrical System & Preventive & 2 months & 45 \\
\hline Packing Changes & Corrective & Weekly & 280 & Electric Engine Maintenance & Preventive & 2 months & 70 \\
\hline Filter Cleaning & Corrective & Weekly & 180 & Wheel Bearing Changes & Preventive & 3 months & 15 \\
\hline & & & 380 & & & & 1630 \\
\hline
\end{tabular}

Figure 7. Maintenance Times Before and After Autonomous Maintenance Application.

The model proposed the application of autonomous and preventive maintenance tools, which reduced downtimes by 36.17 hours. 
The 9th AIC 2019 on Sciences \& Engineering (9thAIC-SE)

IOP Publishing

IOP Conf. Series: Materials Science and Engineering 796 (2020) 012006 doi:10.1088/1757-899X/796/1/012006

\subsubsection{Preventative Maintenance}

The preventive maintenance process was redesigned as per the flowchart described in Figure 7:

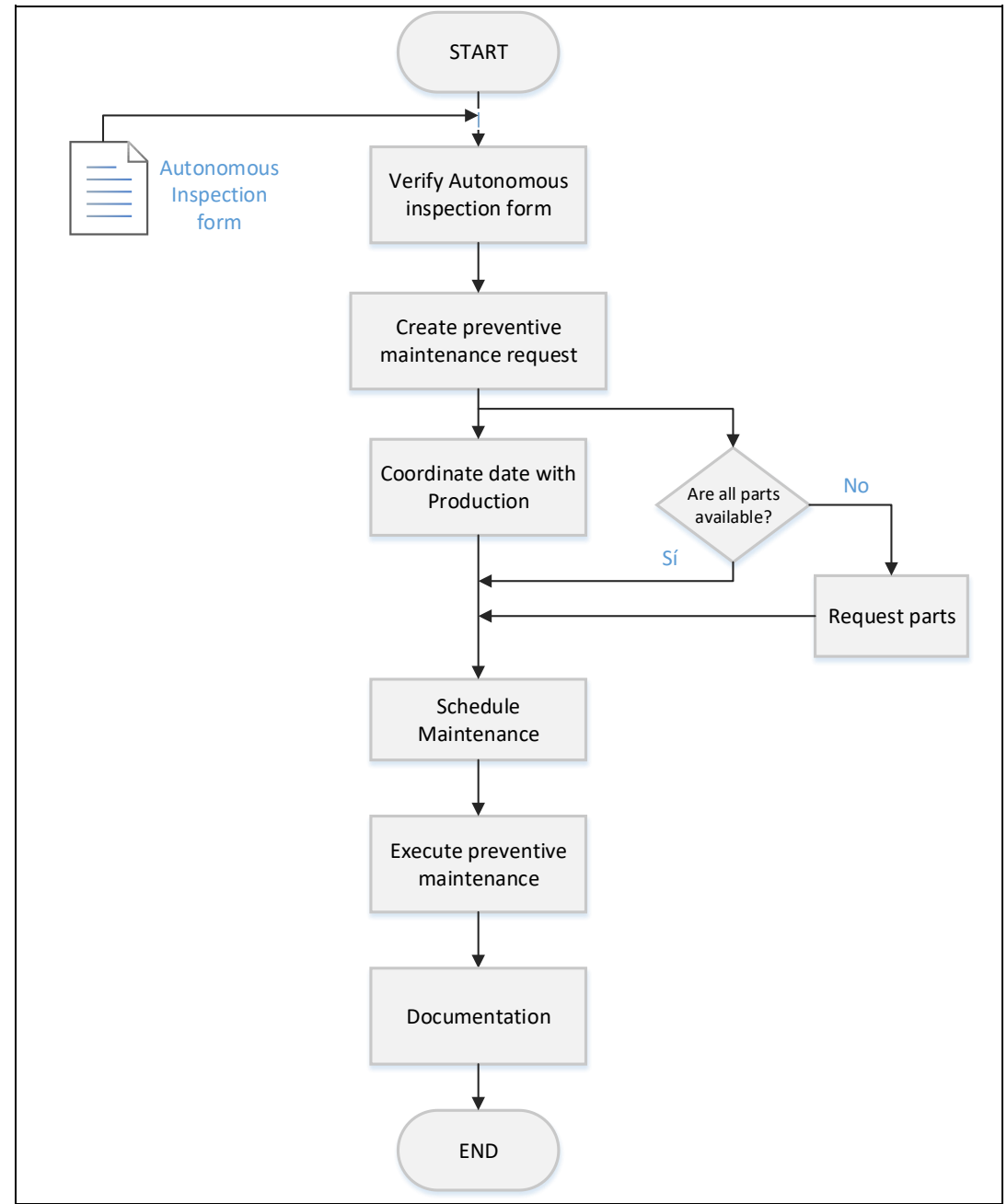

Figure 8. Autonomous Maintenance Flowchart

\subsubsection{Verification: Metrics from Indicators}

Table 2. Results from initial and final indicator data

\begin{tabular}{lcc}
\hline & Initial data & Final data \\
\hline MTBF & $4.45 \mathrm{hrs}$ & $6.30 \mathrm{hrs}$ \\
OEE & $52.15 \%$ & $68.66 \%$ \\
Quality & $98.43 \%$ & $98.68 \%$ \\
Performance & $71.98 \%$ & $82.80 \%$ \\
Availability & $73.61 \%$ & $84.03 \%$ \\
CM & $67.00 \%$ & $91.00 \%$ \\
Machine Breakdowns & $26.39 \%$ & $15.97 \%$ \\
Maintenance cost per unit & $19.57 \%$ & $16.44 \%$ \\
\hline
\end{tabular}


The data and times were taken before and after implementing the pilot plan to validate the achievement of objectives and to measure their progress.

\section{Conclusions}

- Model implementation reported a 39\% reduction in downtimes, which increases production by 748 tons per year. This represents revenue of $\$ 405,770$ obtained during the 6 -month period in which the model was implemented.

- Further, overall machine availability experienced a $14 \%$ increase, which improves average times between breakdowns by $40 \%$.

- Finally, maintenance costs were reduced from $19.57 \%$ to $16.44 \%$ per ring block, thus generating a $3 \%$ reduction in total production costs.

\section{References}

[1] PROMPERÚ 2018 Developing Fishing and Aquaculture Foreign Trade (Lima).

[2] SNI 2016 "Number of Fishing Plants," (Lima).

[3] Vorne 2011 Lean Production. Retrieved from: www.leanproduction.com/.

[4] PRODUCE 2015 ANUARIO ESTADÍSTICO PESQUERO Y ACUÍCOLA (Lima).

[5] Fullerton R, Kennedy F A and Widener S K 2014 Lean manufacturing and firm performance: The incremental contribution of lean management accounting practices $J$ Oper Manag Management, 32(7-8) 414-428.

[6] MINCETUR 2016 Peruvian Giant Squid in the Spanish Market (Lima).

[7] Lastra F, Meneses N, Altamirano E, Raymundo C, Moguerza J M 2019 Production management model based on lean manufacturing for cost reduction in the timber sector in Peru Adv Intel Syst Comput 971 467-476.

[8] Gupta P and Vardhan S 2016 Optimizing OEE, productivity and production cost for improving sales volume in an automobile industry through TPM: a case study Int J Prod Res 54 (10) 2976-2988.

[9] Ahuja I and J S K 2008 Total productive maintenance: literature review and directions," Int J Qual Relia Manag 25 (7) 709-756.

[10] Peimbert-García R, Limon-Robles J, Beruvides M and García-Hernández D 2012 An economic framework for total productive maintenance (TPM) 2222-2231.

[11] Wickramasinghe and Perera A 2016 Effect of total productive maintenance practices on manufacturing perfomance: Investigation of textile and apparel manufacturing firms $J$ Manuf Tech Manag 27 713-729.

[12] Rodrigues M and Hatakeyama K 2006Analysis of the fall of TPM in companies $J$ Mater Process Tech 179(1-3) 276-279.

[13] Sukdeo N 2017 The application of 6S methodology as a lean improvement tool in an ink manufacturing company IEEE International Conference on Industrial Engineering and Engineering Management (IEEM) (Johannesburgo).

[14] Bataineh O, Al-Hawari T, Alshraideh H and Dalalah D 2019 A sequential TPM-based scheme for improving production effectiveness presented with a case study," J Qual Maintenance Eng. 